\title{
O DEBATE DA TEORIA POLÍTICA CONTEMPORÂNEA SOBRE A “LIBERDADE” E UM ESBOÇO DE CRÍTICA SOCIOLÓGICA
}

\author{
The debate of contemporary political theory on "freedom" and a sketch of \\ sociological criticism
}

\author{
Lucas VOIGT \\ Doutorando do Programa de Pós-Graduação em \\ Sociologia \\ Universidade Federal do Rio Grande do Sul, \\ Porto Alegre, Brasil \\ lucas_3106@hotmail.com \\ https://orcid.org/0000-0001-9789-7851 (i)
}

\author{
Jean Matheo Piccini LAGO \\ Mestre em Sociologia Política \\ Universidade Federal de Santa Catarina, \\ Florianópolis, Brasil \\ jean8884@hotmail.com \\ https://orcid.org/0000-0002-4197-3859
}

\section{RESUMO}

O artigo tem por objetivo realizar um mapeamento do debate contemporâneo sobre o problema da liberdade na teoria política e, de modo correlato, apresentar um esboço de crítica sociológica à discussão. Na primeira parte do texto, são apresentados os três principais conceitos de liberdade na teoria política: a liberdade como não-interferência, a liberdade como autorrealização e a liberdade como não-dominação. Na segunda parte, são apresentados alguns dos fundamentos subjacentes ao debate sobre a liberdade, confrontando as principais formulações de três correntes do debate teórico-político contemporâneo: o liberalismo, o comunitarismo e o republicanismo. Na terceira e última parte, procedemos à elaboração de um esboço de crítica sociológica às concepções sobre a liberdade na teoria política. $O$ artigo propõe a demarcação de uma distinção fundamental entre as duas disciplinas no que tange ao problema da liberdade, levando em conta dois aspectos: a constituição teórica e epistemológica dos dois campos disciplinares (filosofia moral $x$ ciência objetiva) e o objeto de referência para a análise das restrições à liberdade (Estado $x$ sociedade).

PALAVRAS-CHAVE: Liberdade. Teoria Política. Sociologia. Liberalismo. Republicanismo.

\begin{abstract}
The article aims at mapping the contemporary debate on the problem of freedom in political theory and, in a related way, presenting a sketch of sociological critique to the discussion. In the first part of the text, the three main concepts of freedom in political theory are presented: freedom as non-interference, freedom as self-realization and freedom as nondomination. In the second part, some of the theoretical grounds underlying the debate on freedom are presented, confronting the main formulations of three traditions of the contemporary theoretical-political debate: liberalism, communitarianism and republicanism. In the third and final part, we proceed to the elaboration of a sketch of sociological critique of conceptions about freedom in political theory. The article proposes the demarcation of a fundamental distinction between the two disciplines with regard to the problem of freedom, taking into account two aspects: the theoretical and epistemological constitution of the two disciplinary fields (moral philosophy vs. objective science) and the object for reference in the analysis of the restrictions of freedom (State vs. society).
\end{abstract}

KEYWORDS: Freedom. Political Theory. Sociology. Liberalism. Republicanism. 


\section{O DEBATE SOBRE O CONCEITO DE LIBERDADE NA TEORIA POLÍTICA CONTEMPORÂNEA}

Para realizarmos um mapeamento do debate sobre o problema da liberdade, é imperioso que principiemos pelo teórico político que lançou as bases e definiu os termos do debate contemporâneo sobre o tema, Isaiah Berlin (2002). Em seu famoso ensaio intitulado Two Concepts of Liberty, publicado originalmente em 1958, Berlin irá reconhecer que o termo liberdade possui um caráter polissêmico. Visando organizar sua argumentação, o autor irá discutir dois dos principais sentidos atribuídos à noção. De acordo com Berlin, existem dois conceitos distintos e incomensuráveis de liberdade, a "liberdade negativa" e a "liberdade positiva". Nas palavras do autor: "Não são duas interpretações diferentes de um único conceito, mas duas atitudes profundamente divergentes e irreconciliáveis para com os fins da vida" (BERLIN, 2002, p. 267). Portanto, trata-se de duas concepções de liberdade que partem de pressupostos distintos e dão respostas diferentes no tocante ao que constitui o homem. Assim, os dois conceitos de liberdade representam um conflito entre dois sistemas de ideias que dão respostas distintas a questões centrais da teoria política - como a obediência e a coerção.

O conceito de liberdade negativa ("liberdade de") se refere a uma área mínima em que o sujeito deve ter permissão de fazer o que é capaz de fazer, sem sofrer interferência de outros. Por outro lado, a liberdade positiva ("liberdade para") se refere à fonte de controle ou interferência capaz de determinar que um sujeito faça alguma coisa ao invés de outra.

No tocante à noção de liberdade negativa, Berlin argumentará que alguém é considerado livre na medida em que ninguém interfira em sua atividade. Nas palavras do autor:

A liberdade política nesse sentido é simplesmente a área na qual um homem pode agir sem ser obstruído por outros. Se outros me impedem de fazer o que do contrário eu poderia fazer, não sou nessa medida livre; e, se essa área é restringida por outros homens além de certo valor mínimo, posso ser descrito como coagido ou, talvez, escravizado. (BERLIN, 2002, p. 229).

Berlin irá apontar a necessidade de problematização do termo coerção. À maneira de Hobbes, o autor afirma que nem toda forma de incapacidade pode ser compreendida como "coerção". Para os autores, um dos fundamentos da liberdade é o poder de agir em 
busca de um objetivo determinado; se um indivíduo está desprovido de tal poder em função de uma incapacidade individual, tal fato não representa uma restrição de sua liberdade. Assim, compreende-se que a coerção é a interferência deliberada de agências externas na atividade de um sujeito, atuando sobre seu corpo ou sua vontade, restringindo as suas possibilidades de ação.

Segundo Berlin, essa é a concepção dos filósofos políticos ingleses clássicos. Em tal visão, a liberdade não poderia ser ilimitada ("liberdade natural"), pois se todos os homens pudessem interferir de forma ilimitada na vida de todos os outros, resultaria 0 caos social. Tais filósofos concordavam em restringir a liberdade em função de outras metas (como justiça, segurança, etc.). Assim, a questão primordial se torna identificar a amplitude dessa área de não interferência. Não obstante, os filósofos do período - como Locke, Mill ${ }^{1}$, Constant e Tocqueville - concordavam que uma área mínima de liberdade não poderia ser violada e, assim, era necessário traçar uma fronteira entre a vida privada e a autoridade pública.

De acordo com Berlin, filósofos tão diversos como Locke, Adam Smith e Hobbes concordavam que uma área da experiência individual deveria permanecer livre do controle social. Nas palavras do autor:

O mais eloquente de todos os defensores da liberdade e privacidade, Benjamin Constant, que não se esquecera da ditadura jacobina, declarou que, no mínimo, a liberdade de religião, opinião, expressão e propriedade tinha de ser garantida contra uma invasão arbitrária. (BERLIN, 2002, p. 233).

Entretanto, Berlin irá argumentar que não há consenso sobre a área mínima de não interferência, questão que foi - e ainda é - alvo de inúmeros debates ${ }^{2}$.

O segundo conceito de liberdade, a liberdade positiva - a "liberdade para" levar uma forma prescrita de vida - é, segundo Berlin, um disfarce para a tirania. Tal sentido do termo liberdade provém do desejo do homem de ser seu próprio senhor, referindo-se ao seu desejo de ser sujeito - e não objeto -, e de ser guiado pela razão e por objetivos

\footnotetext{
${ }^{1}$ Um dos principais interlocutores de Berlin é John Stuart Mill, que postulava a importância da liberdade pessoal para o progresso da civilização, para a originalidade e para o alcance da verdade (MILL, 2001). Não obstante, Berlin procura se distanciar de Mill, visto que não corrobora a tese de que a liberdade é condição necessária para o desenvolvimento do gênio humano.

${ }^{2}$ Segundo Berlin, quanto maior a área de não interferência maior é a liberdade. Assim, podemos falar de gradações de liberdade, não apenas de sua existência (ou inexistência). Berlin não oferece uma discussão no tocante à mensuração da liberdade. Segundo Silva (2015), tal discussão tem sido proposta pelo filósofo político lan Carter, que formulará uma teoria sobre a mensurabilidade da liberdade.
} 
conscientes $^{3}$. Ser livre, nesse caso, seria ser consciente de si como um sujeito que age, pensa e tem vontade; o contrário implicaria em escravidão. A liberdade pode ser entendida aqui como "autodomínio", ou "autorrealização". Nessa visão, a não interferência na performance de uma ação qualquer não é o elemento determinante para que tal ação seja considerada livre; na liberdade positiva, é necessário que a ação de um sujeito seja um meio para a sua "autorrealização", expressando o "domínio" do indivíduo sobre si mesmo, seus impulsos e suas paixões.

Tal concepção parte da suposição de uma cisão entre um "eu" que domina e outra dimensão que é controlada. Esse eu dominante é concebido de distintas formas: razão, natureza "mais elevada", eu "real", "ideal", "autônomo", que é contrastado com os impulsos irracionais, os desejos, a busca de prazeres, e assim por diante. Segundo Berlin, o "eu real" pode ser compreendido como algo mais amplo do que o indivíduo, isto é, como um conjunto social - raça, classe, Igreja, Estado etc. Essa identidade seria identificada com o eu "verdadeiro" que, impondo sua vontade coletiva aos seus membros, alcançaria a sua liberdade "mais elevada" e também a de seus membros.

A liberdade positiva justificaria a coerção de alguns homens a fim de alçá-los a um nível mais elevado de liberdade. Tratar-se-ia de uma coação visando o bem e os interesses de outrem. Em tal visão, parte-se da suposição de que não haveria coerção se os indivíduos recalcitrantes fossem tão racionais quanto o agente perpetrador da coerção. Nesta perspectiva, as pessoas visariam "realmente" aquilo que conscientemente resistem, pois existiria uma "vontade racional latente", um "verdadeiro propósito" para a sua vida. Nas palavras de Berlin:

Uma vez adotada essa visão, estou em posição de ignorar os desejos reais dos homens ou das sociedades, de amedrontá-los, oprimi-los, torturá-los em nome e no interesse de seus eus "reais", com base no conhecimento seguro de que tudo o que é a verdadeira meta do homem (a felicidade, o desempenho do dever, a sabedoria, uma sociedade justa, a auto-realização) deve ser idêntico à sua liberdade - a escolha livre de seu eu "verdadeiro", ainda que frequentemente submerso e inarticulado. (BERLIN, 2002, p. 238).

$\mathrm{Na}$ perspectiva de Berlin, toda interpretação da palavra liberdade deve incluir minimamente a liberdade negativa. O objetivo de seu célebre ensaio é chamar a atenção dos liberais, que consubstanciavam os dois conceitos de liberdade. Segundo o autor, o

\footnotetext{
${ }^{3}$ É interessante notarmos que a definição de liberdade positiva encontra repercussão na sociologia clássica. Segundo Durkheim: "Ser livre não é fazer o que se quer; é ser senhor de si mesmo" (apud GIDDENS, 2011, p. 145). Para a principal obra política de Durkheim, que opera uma defesa do Estado e uma crítica à "liberdade negativa", ver Durkheim (2013).
} 
sentido positivo da liberdade pode destruir muitas das liberdades negativas. Assim, podese afirmar que os principais inimigos de Berlin são os liberais hegelianos, que defendem um sentido positivo para a liberdade. Desta forma, o ensaio de Berlin pode ser compreendido como uma defesa do sentido negativo da liberdade, noção associada à tradição do individualismo liberal. Além de defensor do liberalismo, Berlin pode ser definido como um pluralista, isto é, um crítico do monismo - de um valor único para o ordenamento das sociedades humanas. De acordo com o autor, existiriam inúmeras metas para a humanidade; assim, seria impossível encontrar um objetivo único - racional, verdadeiro e universal - que pudesse justificar a coerção dos homens e a eliminação de sua liberdade negativa.

Seguindo a linha argumentativa sugerida por Berlin no tocante à irredutibilidade da discussão sobre liberdade a um único conceito, autores como Philip Pettit (2004) e Quentin Skinner (2002) irão "reviver" uma terceira forma de conceitualizar a liberdade, que - segundo os autores - fora esquecida no debate da teoria política contemporânea. Assim, tais autores - afiliados à perspectiva do republicanismo neorromano - irão introduzir no debate contemporâneo da teoria política o conceito de liberdade como nãodominação.

Segundo tal perspectiva, as ideias do utilitarismo clássico - desenvolvidas por pensadores como Thomas Hobbes, Jeremy Bentham, John Stuart Mill e Henry Sidgwick ocuparam em boa medida o espaço conceitual da liberdade negativa. É precisamente retomando Hobbes, e o debate no qual estava envolvido durante o desenvolvimento de seu conceito de liberdade, que Skinner e Pettit encontram o momento em que esse terceiro conceito perdeu importância na teoria política.

Já se sabe que a definição de liberdade desenvolvida por Hobbes é a da "liberdade negativa". A presença de liberdade é sempre marcada por uma ausência, a de interferência. Em Hobbes, Pettit (2004) encontra a ideia de que a lei em si mesma é uma forma de invasão da liberdade, ainda que possa ser justificada. A lei é uma forma de interferência; mesmo que incremente a liberdade a posteriori, isso se deve a um efeito compensatório, ao inibir a interferência de outros. Segundo o autor, essa relação entre lei e liberdade também é encontrada em outros autores, como Berlin, Bentham e Rawls.

De acordo com Pettit (2004), a definição sobre a relação entre lei e liberdade proposta por Hobbes é uma resposta direta à definição republicana. Para os republicanos, são as leis de um Estado adequado (isto é, de uma república) que criam a liberdade de 
que desfrutam os cidadãos. Tal concepção emerge da noção de cidadania (civitas) como um status que necessariamente só pode se dar em um regime legal apropriado.

Skinner (2002) afirma que a base para a definição republicana de liberdade encontra-se no Codex of Roman Law e em Codifications of Common Law. Em tais documentos, está marcada a distinção entre o liber homo (isto é, o homem ou mulher livre) e o escravo. Para a lei romana, todos seriam "livres" ou "escravos". A escravidão é uma instituição pela qual alguém, contrariamente à natureza, é sujeito à dominação de outra pessoa. A partir disso, o autor argumenta que se todos em associações civis são livres ou escravos, então um liber homo deve ser alguém que não está sob a dominação de outra pessoa.

Skinner (2002) irá argumentar também que a liberdade é cerceada não somente nos momentos em que os governantes usam o seu poder para interferir, mas que a simples existência de uma prerrogativa legal para que o governo possa - em determinadas situações - usar de poderes discricionários ou arbitrários, tem por efeito uma restrição da liberdade. Em tal contexto, a propriedade e a liberdade não se dariam por direito, mas pela graça dos dominantes. Isto é, elas não teriam o status de direitos, mas sim de licenças e privilégios.

Para explicitar tal ideia, Philip Pettit irá citar James Harrington, um importante pensador republicano:

[...] "El hombre que no puede vivir por sí mismo debe ser un sirviente; pero aquel que puede vivir por sí mismo puede ser un hombre libre". Para Harrington, lo peor de la falta de libertad es tener que vivir de acuerdo con la voluntad de otro - la voluntad arbitraria de otro - igual que lo hace un esclavo; la esencia de la libertad es no tener que suportar esta dependencia y vulnerabilidad. (PETTIT, 2004, p. 121).

Seguindo tal linha de pensamento, depreende-se de Skinner (2002) que, na concepção republicana, "ser escravo" é estar dependente da vontade de outra pessoa. Em tal contexto, a vontade de um sujeito é determinada pela vontade de outrem e, por consequência, o sujeito não tem o poder - ou a liberdade - de agir segundo a sua própria vontade ou determinação. Todas as suas ações têm o caráter de "permissões", na medida em que elas devem estar de acordo com a vontade do "mestre" ou "amo". Admitir tal situação é, em última instância, aceitar que se vive subjugado à vontade de um dominante, e admitir que os sujeitos não são livres, mas escravos. O conhecimento de tal fato serviria em si mesmo para diminuir a liberdade e relegar os indivíduos à servidão. 
Portanto, na concepção republicana, a liberdade depende não apenas das ações concretas de um indivíduo - isto é, da sua "interferência" -, mas principalmente dos poderes à sua disposição. Assim, estar em uma relação em que outros têm o poder de interferir - mesmo que não o façam -, constitui uma relação de dependência em relação à boa vontade ou misericórdia de um dominante. Dito de outro modo, em uma relação de dominação, um indivíduo está sujeito à interferência - concreta ou virtual - de outro indivíduo. No momento em que emerge a consciência dessa assimetria de poder pelo dominado, novas implicações se produzem em relação à liberdade. Isto é, a partir do momento em que o sujeito reconhece que outro indivíduo tem o poder de interferir no curso de sua ação, sem nenhum poder de defesa, tal fato acarreta autocensura, na medida em que o dominado adapta a sua ação de forma a evitar a interferência ou a coação por parte do dominante.

Deve-se destacar, por fim, que na perspectiva republicana a percepção da relação entre dominante e dominado é estrutural. De acordo com Pettit (2004), comparando as definições de liberdade entre o liberalismo e o republicanismo, a principal distinção reside precisamente em tal percepção estrutural do conceito de liberdade. Enquanto que, para os liberais, a liberdade pode ser resumida à não interferência, para os republicanos ela significa, além da não interferência, a garantia de que outros não terão a possibilidade de interferir voluntariamente nas ações de um indivíduo. Assim, a distinção reside precisamente na percepção estrutural, haja vista que os republicanos constroem um modelo com diferentes posições - civis e governantes -, nas quais, para haver liberdade, nenhuma posição deve possuir o poder - mesmo que não o exerça - de interferir arbitrariamente nas ações de outros.

\section{FUNDAMENTOS TEÓRICOS E POLÍTICOS PARA O DEBATE SOBRE A LIBERDADE: LIBERALISMO, COMUNITARISMO E REPUBLICANISMO}

Esta seção tem por objetivo apresentar algumas reflexões sobre os fundamentos teóricos e políticos subjacentes ao debate sobre a liberdade, analisando três vertentes ou "tradições" - do pensamento político contemporâneo: o liberalismo político, o comunitarismo e o republicanismo. Por um lado, a análise de tais perspectivas teóricas e das críticas, acusações e oposições que estabelecem entre si - possibilita uma 
compreensão aprofundada das distintas concepções sobre a liberdade previamente discutidas, por meio da explicitação dos fundamentos filosóficos e dos sistemas de valores - e, em última instância, das concepções sobre o que constitui o "homem" e a "boa sociedade" - subjacentes aos distintos conceitos de liberdade. Por outro lado, a explicitação das principais correntes teóricas no campo da teoria política contemporânea contribuirá, posteriormente, para o desenvolvimento de um esboço de crítica sociológica ao debate sobre a liberdade nos marcos da teoria política - objeto de análise que ocupará a última sessão deste artigo. Como veremos, compreender as críticas e as oposições entre as correntes teóricas nos embates da teoria política contemporânea, mostrar-se-á de grande valia para a demarcação de fronteiras e distanciamentos entre as perspectivas teórico-política e sociológica no tocante ao problema da liberdade humana.

\subsection{Liberalismo político}

O principal e mais influente conceito de liberdade na teoria política, a liberdade como não-interferência, é marcado por uma perspectiva liberal e individualista. À nossa discussão, é interessante apontarmos alguns elementos dessa perspectiva, pois é com base em uma crítica às diversas formas do individualismo - notadamente nas suas versões "atomista" e "voluntarista" - que a sociologia tem se desenvolvido; ademais, é levando em conta a crítica ao isolacionismo do indivíduo e a teorias que ignoram o papel das relações e das interdependências sociais para a constituição a priori da individualidade, que proporemos repensar o tema da liberdade a partir de uma perspectiva sociológica.

Para discutirmos a perspectiva liberal e o individualismo, nos basearemos em um dos seus expoentes contemporâneos, a saber, John Rawls (1993). No aclamado $A$ Theory of Justice, publicado originalmente em 1971, Rawls irá formular uma teoria da justiça como equidade, visando reatualizar a tese clássica do contratualismo. O objetivo do autor é analisar os desenvolvimentos que devem levar a um acordo inicial sobre princípios de justiça. Para Rawls, o conceito de justiça é a carta fundamental de uma boa sociedade humana, determinando direitos e deveres das instituições, bem como a distribuição de benefícios e deveres da cooperação social. Assim, a justiça social assume como principal tema a estrutura básica da sociedade - e tal estrutura constitui-se como o sujeito primário da justiça. 
No liberalismo político de Rawls, a eleição da justiça como o princípio primordial da sociedade pode ser compreendida como uma contraposição às teses do utilitarismo clássico, principalmente na versão formulada por Jeremy Bentham, que proporá o princípio da "maximização da felicidade". Na visão utilitarista, a melhor ação é aquela que produz a maior quantidade de felicidade para o maior número de pessoas. Na visão de Rawls, entretanto, uma ação que produz a maior felicidade agregada ainda pode produzir sofrimento para alguns membros do agrupamento social, representando, assim, uma injustiça em relação a determinados indivíduos.

O objetivo de Rawls é formular um conceito de justiça que reelabore as formulações da teoria do contrato social, tal como proposta por pensadores como Locke, Rousseau e Kant. Desta feita, segundo Rawls, o contrato original não define a entrada do indivíduo numa sociedade; seu objeto é a definição dos princípios de justiça para a estrutura básica da sociedade. Nas palavras do autor:

Estes princípios são os que pessoas livres e racionais, reunidas pelos mesmos interesses, adotariam inicialmente quando todos estivessem numa posição de igualdade, para definir os termos fundamentais da associação que estariam fazendo. (RAWLS, 1993, p. 158).

Esta concepção de justiça é a da "justiça como equidade". Segundo o autor, a escolha de um homem racional nessa condição hipotética, onde todos são igualmente livres, determina os princípios de justiça.

De acordo com Rawls, os princípios de justiça são definidos com base na ignorância do indivíduo em relação à posição social que ocupa, bem como em relação à posição dos demais. Nessa posição original, é possível a equitatividade dos acordos realizados, pois todos estariam em posição de igualdade para definir os princípios do contrato. Tal formulação está associada à célebre ideia de "véu de ignorância", isto é, à suposição de que o indivíduo não sabe como as alternativas irão the influenciar, devendo avaliar os princípios meramente com base em considerações gerais. Rawls reconhece que a posição inicial é hipotética, e que tal acordo jamais tenha ocorrido de fato. Não obstante, segundo o autor, a noção tem utilidade, pois os princípios aceitos em tal situação são passíveis de aceitação por meio de reflexão filosófica. $O$ fato de pessoas livres e racionais, em pé de igualdade, terem hipoteticamente escolhido a justiça como 
princípio central da sociedade atribuiria, assim, legitimidade à ideia de justiça como equidade ${ }^{4}$.

Rawls irá identificar dois princípios de justiça que podem ser escolhidos na posição inicial. O primeiro, especialmente interessante à nossa discussão, na medida em que explicita a perspectiva liberal do autor, é que "cada pessoa deve ter a mais ampla liberdade, sendo que esta última deve ser igual à dos outros e a mais extensa possível, na medida em que seja compatível com uma liberdade similar de outros indivíduos". (RAWLS, 1993, p. 163). Este é o princípio da liberdade. O segundo princípio, o princípio da diferença, postula que "as desigualdades econômicas e sociais devem ser combinadas de forma a que ambas (a) correspondam à expectativa de que trarão vantagens para todos, e (b) que sejam ligadas a posições e órgãos abertos a todos”. (RAWLS, 1993, p. 163). O primeiro princípio se associa à atribuição de direitos e deveres. Dentre as liberdades básicas do cidadão, Rawls elenca a liberdade política, de expressão, de reunião, de pensamento, pessoal (associada à propriedade), e a liberdade de não ser preso arbitrariamente. O segundo princípio regula a distribuição de renda e de bens. Para o autor, o primeiro princípio deve preceder o segundo, isto é, maiores vantagens econômicas ou sociais não podem ser justificativas para a limitação das liberdades básicas. Em outras palavras, a liberdade só pode ser restringida pela própria liberdade.

Rawls irá afirmar que a teoria da justiça como equidade deriva de uma interpretação kantiana da justiça. Segundo o autor, Kant considerava que uma ação autônoma ocorria quando os princípios de ação de uma pessoa eram escolhidos por ela como a melhor expressão possível de sua natureza livre, racional e igual. Estes princípios não seriam adotados em virtude da posição social ou de dons naturais do indivíduo, ou em função da sociedade em que vive - o que corresponderia a uma ação heterônoma. Nas palavras de Rawls:

Os princípios da sua ação não dependem de contingências sociais ou naturais, nem refletem os preconceitos individuais dos seus planos de vida ou das aspirações que os motivam. Agindo a partir destes princípios, as pessoas expressam a sua natureza como entes racionais, livres e iguais, sujeitos às condições gerais da vida humana, pois, expressar a natureza de alguém como um ente de tipo específico significa agir sobre princípios que seriam escolhidos se esta natureza fosse 0 decisivo elemento determinante. (RAWLS, 1993, p. 180).

\footnotetext{
${ }^{4}$ Segundo Rawls (1993), a teoria da justiça, ao assumir que na posição original as pessoas seriam racionais e que buscariam a alternativa mais racional possível, se liga à teoria da escolha racional.
} 
Para Rawls, os princípios da justiça - dentre eles a liberdade, o primeiro e mais importante princípio - são imperativos categóricos no sentido kantiano, isto é, um princípio de conduta aplicável à pessoa em virtude de sua natureza racional, livre e igual. Ademais, tais reflexões, que supõem a existência de uma natureza intrínseca ao indivíduo, explicitam o ponto de partida individualista da teoria de Rawls. Este ponto é relevante, pois como veremos em detalhes na discussão sociológica apresentada mais à frente, é pouco plausível supormos que qualquer ação do indivíduo seja "autônoma", no sentido de que independa da posição social ou da interferência da sociedade na qual o indivíduo está inserido.

Rawls entende que o sistema social forma os desejos e as aspirações que os cidadãos venham a ter. Neste sentido, o próprio autor reconhece que a influência do sistema social sobre os desejos humanos e sobre a concepção do homem acerca de si mesmo pode lançar objeções à doutrina contratualista. A resposta dada pelo autor a tal objeção, entretanto, é pouco convincente. Rawls irá afirmar que apenas os pressupostos mais gerais são definidos no contrato; assim, a justiça e o ideal de uma sociedade justa não estariam à mercê dos interesses e das vontades produzidos socialmente. Deste modo, o autor expressa uma concepção ideal da pessoa e da justiça, apriorística.

Em nossa visão, chega a ser até mesmo surpreendente que um autor com limitações e fragilidades teóricas tão notáveis tenha alcançado tamanha influência e repercussão no debate teórico-político. Dentre tais limitações teóricas, podemos mencionar, em primeiro lugar, a perspectiva caracteristicamente anistórica da obra de Rawls. Uma das principais fragilidades do trabalho do autor é a assunção de uma posição original hipotética de igualdade para a identificação dos princípios racionalmente escolhidos para a estrutura básica da sociedade, na medida em que, historicamente, tal condição de igualdade não pode ser verificada. Caso uma perspectiva histórica fosse empregada, noções como "posição original", "véu da ignorância" e "equidade" certamente dariam lugar a termos como conflito, violência e dominação. Em segundo lugar, embora Rawls reconheça o caráter hipotético de sua formulação, deve-se pontuar que sua obra procede à explicação de fenômenos concretos, históricos e observáveis - tais como a justiça, a constituição, o Estado, etc. - com base em formulações hipotéticas, idealistas e não demonstráveis. Por fim, deve-se destacar uma última limitação da teoria da justiça como equidade - a mais importante à nossa discussão, da qual trataremos de modo continuado no decorrer deste artigo -, a saber, o emprego de uma perspectiva 
individualista completamente indiferente e alheia à influência e à interferência dos determinantes sociais na ação do indivíduo.

\subsection{Comunitarismo}

Em teoria política, é no comunitarismo que encontramos uma crítica parcialmente semelhante a John Rawls, ao liberalismo e ao individualismo. Os expoentes dessa corrente são Michael Sandel, Charles Taylor e Alasdair Maclntyre. Para fins de análise, iremos apresentar alguns dos argumentos formulados por Michael Sandel (2004) em seu famoso ensaio The Procedural Republic and the Unencumbered Self 5 , publicado originalmente em 1984.

De acordo com Sandel (2004), o liberalismo dá ênfase à justiça, à equidade e aos direitos individuais. Na perspectiva liberal, uma sociedade justa não deve promover nenhum fim específico, mas permitir que seus cidadãos persigam seus próprios fins, garantindo uma liberdade similar a todos. Nessa concepção, o "correto" precederia o "bom", isto é, os direitos individuais não podem ser sacrificados em nome de um bem geral; além disso, os princípios de justiça não podem se apoiar em uma concepção particular da "boa vida". Dito de outro modo, os liberais buscariam o "correto" - ou seja, permitir que os indivíduos persigam uma variedade de fins -, e não o "bem" - isto é, um Estado promovendo um fim específico. Nas palavras de Sandel (2004, p. 78): “La ética liberal sostiene la prioridad de lo correcto y busca principios de justicia que no presupongan ninguna concepción de lo bueno".

Em seu ensaio, Sandel (2004) discutirá a concepção do indivíduo - um "agente moral" - subjacente ao liberalismo. Essa concepção é definida como a do "eu desvinculado". Inicialmente, o autor discutirá as concepções de Kant sobre o sujeito. Em tal perspectiva, um sujeito - isto é, aquele que é capaz de uma vontade autônoma - seria a base da lei moral. Desta forma, o ser racional em si mesmo seria o fim de todas as ações. Como vimos, esse sujeito seria independente de quaisquer inclinações sociais ou psicológicas. Assim, na visão kantiana, o indivíduo escaparia do reino da natureza e dos fins meramente empíricos. Esse sujeito somos "nós" enquanto integrantes da "razão pura prática", de um "sujeito transcendental". A concepção kantiana do sujeito não se refere

\footnotetext{
${ }^{5}$ O termo unencumbered self pode ser traduzido como "eu desonerado", "eu desvinculado" - como na tradução espanhola (SANDEL, 2004) - ou ainda "eu desresponsabilizado". O termo visa descrever a concepção liberal do homem, que o desassociaria da sociedade.
} 
assim, ao ser empírico, cujos atos são condicionados por objetos e, portanto, incapaz de liberdade. De acordo com Sandel (2004), Rawls procura desenvolver uma concepção kantiana viável da justiça, reconstituindo o idealismo transcendental característico de Kant em um empirismo palatável à filosofia anglo-saxônica. Essa é, segundo o autor, a função da "posição original" em seu modelo teórico.

Como argumenta Sandel (2004), a teoria de Rawls pressupõe uma concepção da pessoa, o "eu desvinculado", que seria anterior a quaisquer fins. O "eu" seria anterior ao fim, ao objeto, à personalidade, à própria pessoa física. Em outras palavras, haveria um sujeito distinto e anterior aos valores e aos desejos que determinado sujeito empírico possui. Ao eu desvinculado importa menos os fins que elegemos, do que nossa capacidade de elegê-los. Na perspectiva de Rawls, os "eus desvinculados" podem se unir em comunidades no sentido cooperativo, mas não podem ser membros de uma comunidade unida por laços morais antes dessa eleição - isto é, não podem formar uma comunidade "constitutiva". Sandel irá resumir a concepção de Kant ("sujeito transcendental") e de Rawls ("eu desvinculado") do seguinte modo:

El yo desvinculado y la ética que él inspira, tomados conjuntamente, sostienen una visión liberadora. Libre de los dictados de la naturaleza y de la determinación de los papeles sociales, el sujeto humano se instala como soberano, como autor de los únicos significados morales que existen. Como participantes de la razón pura práctica, o como partes de la posición original, somos libres de construir principios de justicia sin estar restringidos por ningún orden de valores dado previamente. (SANDEL, 2004, p. 83).

Apesar de reconhecer a força dessa formulação, Sandel (2004) argumenta que não é possível sustentar a vida moral e política com base nessa visão. Para Sandel, é impossível conceber um sujeito sem considerá-lo como membro de uma família, de uma comunidade e de uma república. Segundo o autor, o eu desvinculado não possuiria caráter e seria destituído de moral. Nas palavras de Sandel (2004, p. 87):

Imaginar a una persona incapaz de tener vínculos constitutivos como éstos no es concebir a un agente idealmente libre y racional, sino imaginar a una persona carente de carácter, sin profundidad moral.

Para Sandel, em se tratando de política, não se pode ignorar os vínculos constitutivos de comunidades orientadas para um bem comum. 
De acordo com Sandel (2004), associada à precedência liberal do eu em relação aos fins e do correto em relação ao bom, encontra-se ainda a noção de "república procedimental", isto é, a vida pública orientada pela visão e pela autoimagem liberal. A república procedimental operaria uma desvinculação da comunidade da qual depende. À república procedimental, que persegue o correto, se oporia - segundo Sandel - a "república nacional", que persegue o bom.

Para explicitarmos o argumento comunitarista e suas críticas ao liberalismo - bem como para dar voz à réplica dos liberais a tais críticas -, será útil lançarmos mão de uma síntese sobre o debate, elaborada por Will Kymlicka (2006). Kymlicka - autor que se insere dentro da tradição liberal e que se posiciona como um crítico do comunitarismo ${ }^{6}$ argumenta que os comunitaristas irão criticar o liberalismo, em grande medida, por este negligenciar as precondições sociais sobre as quais a capacidade de autodeterminação dos indivíduos se exerce.

Como se sabe, na perspectiva liberal deve haver uma esfera de autodeterminação inviolável do indivíduo. Discutindo as premissas do individualismo liberal e a defesa da neutralidade do Estado, Kymlicka (2006) argumenta que uma "boa vida" deve ser conduzida do interior, segundo as crenças de valor do indivíduo, devendo haver ainda a possibilidade de questionamento dessas mesmas crenças. Desta forma, uma política estatal "perfeccionista" não poderia ser justificada.

Segundo Kymlicka (2006), é a autodeterminação que forma o conceito de liberdade de John Rawls. A liberdade de escolha é importante para que os indivíduos possam encontrar e definir aquilo que é valioso na vida. Assim, o Estado deve agir de modo neutro, não hierarquizando as concepções da "boa vida". Segundo o autor, seria injustificável - em termos morais - a tentativa de impor uma concepção de boa vida às pessoas.

De acordo com Kymlicka (2006), o comunitarismo se opõe de forma categórica ao Estado neutro. Apresentando as ideias propostas por Sandel e Taylor, o autor afirma que os comunitaristas acreditam que o Estado deve perseguir uma política do bem comum. Em uma sociedade comunitária, o bem comum seria uma concepção substantiva da "boa vida" que define a comunidade. É isso que justificaria, em tal perspectiva, a hierarquização pública dos modos de vida por parte do Estado. Segundo Kymlicka, essa oposição sustentada pelos comunitaristas é enganosa, na medida em que o liberalismo

\footnotetext{
${ }^{6}$ Boa parte da crítica se direciona ao fato de que, ao rechaçar o eu desvinculado, Sandel cria uma identidade fixa determinada pela comunidade.
} 
também visa à promoção do bem comum, por meio da combinação das preferências individuais.

Para explicitar o confronto entre liberais e comunitaristas, Kymlicka (2006) irá retomar a tese de Kant e Rawls sobre a primazia do eu em relação aos fins. Segundo o autor:

O comunitarismo acredita que está é uma visão falsa do eu. Ela ignora o fato de que o eu está "inserido" ou "situado" nas práticas sociais existentes, que nem sempre podemos recuar e optar por sair delas. Nossos papeis e relações sociais ou, pelo menos, alguns deles, devem ser considerados como dados para fins de deliberação pessoal. (KYMLICKA, 2006, p. 266).

Na perspectiva comunitarista, que supõe a existência de uma identidade social que determinaria a definição do bem, a autodeterminação só pode ser exercida dentro de papeis sociais.

Segundo Kymlicka (2006), Sandel entende que o eu não é anterior a seus fins, mas constituído por eles. Desta forma, a política do bem comum expressaria os objetivos constitutivos e compartilhados por determinada comunidade. Ao eu desonerado, Sandel contrapõe o "eu inserido". Essa visão implicaria uma "autodescoberta" do que já somos, na medida em que o objetivo perseguido pela comunidade é um elemento constitutivo da identidade do sujeito - em oposição à ideia de "julgamento" defendida pelos liberais, segundo a qual o sujeito avaliaria que tipo de pessoa pretende ser.

Kymlicka (2006) irá apresentar ainda a crítica de Charles Taylor ao liberalismo, segundo a qual as teorias liberais baseiam-se em um "atomismo", isto é, na suposição de que os indivíduos são autossuficientes em relação à sociedade. Taylor advogará em defesa da "tese social", que postula que a capacidade de autodeterminação depende de um determinado tipo de sociedade. A consequência teórica, para Taylor, é a necessidade de que se abandone o Estado neutro e se promova uma política do bem comum. Na visão de Kymlicka (2006, p. 278): "Se este fosse realmente o debate, teríamos que concordar com os comunitários, pois a 'tese social' é claramente verdadeira. A visão de que poderíamos exercer a capacidade de autodeterminação fora da sociedade é absurda”. A resposta de Kymlicka às objeções dos comunitaristas, não obstante, permanece vaga. Ela se limita à afirmação de que liberais como Rawls e Dworkin não negam a tese social, isto é, de que tais autores reconhecem que a autonomia do indivíduo só pode existir em um ambiente social. 
Em nossa visão, a crítica dos comunitaristas ao individualismo liberal é plenamente compreensível e justificada. Como veremos em maiores detalhes a seguir, com base em uma perspectiva sociológica - e de um ponto de vista objetivado e livre de juízos morais , não se pode aceitar a tese de que o indivíduo encontre-se em um estado apriorístico de primazia, na medida em que sua identidade e sua constituição dependem a priori de processos sociais. Deve-se deixar claro, não obstante, que isso não significa uma subscrição às propostas políticas formuladas pelo comunitarismo. O comunitarismo, enquanto uma teoria política, mostra-se igualmente influenciado pela filosofia moral, não rejeitando suposições sobre a "natureza do homem". Ademais, ao rechaçar o eu desvinculado, os comunitaristas postulam a busca do "bem comum" como a finalidade última do Estado e da política. Em última instância, subjaz à proposta comunitarista alçar os valores coletivos em uma posição de primazia em relação ao indivíduo ${ }^{7}$. Em nossa perspectiva - como trataremos de demonstrar na última seção -, em termos de política e de Estado, é lícita e justificável a defesa da não interferência em uma esfera mínima de autodeterminação do indivíduo.

Apesar da convergência no tocante às críticas ao individualismo liberal e ao "eu desvinculado", o comunitarismo se distingue de uma perspectiva sociológica - ou ao menos da perspectiva sociológica que sustentamos neste artigo -, na medida em que, de um ponto de vista objetivado e livre de juízos de valor - o que constitui per se o caráter científico da sociologia -, o reconhecimento da influência e da determinação social na constituição do sujeito não implica - e não deve implicar - uma atribuição de primazia ao "bem comum" e aos valores constitutivos de uma "comunidade" frente ao indivíduo. Dito de outro modo, a constatação do fato inequívoco - e até mesmo óbvio - de que o indivíduo é resultado de múltiplas e complexas interdependências e determinações sociais, não nos autoriza a eleger um "bem comum" específico ou particular, que sirva à justificação e à legitimação da interferência, da coerção e do constrangimento dos indivíduos por parte de um agrupamento social ou político.

\footnotetext{
${ }^{7}$ Os comunitaristas estão próximos de um conceito "positivo" de liberdade. Segundo Berlin (2002), o sujeito da autorrealização, o "eu verdadeiro", pode adquirir uma forma coletiva, como a "comunidade". Ao invés de defender uma área livre de interferência, os comunitaristas promovem o bem comum, por meio da autodescoberta de uma verdadeira natureza, isto é, de uma identidade definida coletivamente.
} 


\subsection{Republicanismo}

Pode-se argumentar que, com a retomada do conceito de liberdade como nãodominação por parte de autores como Philip Pettit e Quentin Skinner, bem como com a profusão de críticas e de descrédito em relação à corrente teórica comunitarista, o republicanismo tomou o espaço previamente ocupado pelos comunitaristas, constituindose como o principal "adversário" do liberalismo no debate teórico-político contemporâneo.

Para a apresentação de alguns dos elementos centrais do argumento republicano e, especialmente, para a identificação das suas críticas e contraposições ao comunitarismo e ao liberalismo, mostra-se profícuo introduzirmos as ideias formuladas por Maurizio Viroli (2002). No que tange ao comunitarismo, o autor é bastante objetivo na demarcação das diferenças e das oposições em relação ao republicanismo. A principal delas reside no fato de que as diversas filosofias comunitaristas propõem, como meio de reviver as virtudes cívicas, o fortalecimento da unidade moral e cultural de um grupo. Isto é, o comunitarismo parte de uma visão centrada na unidade etnocultural da comunidade, a qual possuiria uma tradição cultural compartilhada, incluindo uma concepção moral de bem comum.

Por outro lado, para o republicanismo, a res publica e a civitas constituem-se como uma comunidade política que tem por objetivo permitir que os indivíduos vivam com justiça e liberdade sob o governo de leis. A cidadania, assim, não está vinculada ao pertencimento etnocultural, mas ao pertencimento político. Em tal visão, o bem comum mais importante é a justiça, justamente porque ela cria as condições para que os indivíduos possam viver sem ter que sujeitarem-se à vontade de outros, ou seja, para que possam viver em liberdade. Nas palavras de Viroli (2002, p. 66): "a republic built on a particular conception of goodness, on a particular culture, will not be a republic for everyone, and it will therefore not be just".

Outra distinção apresentada por Viroli (2002) entre as duas tradições de pensamento é a importância atribuída à participação no autogoverno. Enquanto esse é um dos valores mais importantes para os comunitaristas, para os republicanos ele é defendido com algumas ressalvas. Para a tradição republicana, a participação política pode preservar a liberdade e promover a educação cívica, mas deve ser encorajada de modo razoável; mais importante, ela não pode justificar a interferência do Estado na vida dos cidadãos para a promoção de um bem comum. Na visão republicana, a participação 
política é uma maneira de preservar a liberdade; no entanto, geralmente é mais importante escolher bons governantes do que estimular a participação massiva dos cidadãos.

Voltando a sua atenção ao liberalismo, Viroli (2002) irá afirmar que essa doutrina é, do ponto de vista histórico, uma derivação e uma inovação do republicanismo. O autor argumenta que muitos dos princípios do liberalismo - até mesmo aqueles utilizados nos embates com os comunitaristas -, foram formulados primeiramente por pensadores republicanos. Dentre eles está a ideia de que o principal objetivo de uma comunidade política é defender a vida, a liberdade e a propriedade de seus membros individuais. Segundo o autor, esses princípios já haviam sido elaborados por Cícero em De officiis e por Maquiavel nos Discorsi. O mesmo ocorre com outra formulação do liberalismo, a de que o conflito social é inevitável e benéfico, ideia que pode ser retraçada também a Maquiavel nos Discorsi, quando argumenta que o conflito social entre plebeus e o Senado na república romana era um dos fatores mais importantes para a liberdade.

Após apontar as apropriações do liberalismo em relação ao republicanismo, Viroli (2002) irá afirmar que as ideias originais do liberalismo são justamente as mais frágeis. Segundo o autor, tanto a ideia do contrato social, bem como o pressuposto de direitos naturais do homem - noções próprias do liberalismo clássico -, comportam uma fragilidade teórica e explicativa. Enquanto as teorias do contrato social não possuem valor explicativo, os direitos naturais constituem-se como uma abstração, na medida em que direitos só existem realmente caso sejam reconhecidos pela lei ou pelo costume. Desse modo, os direitos são históricos e, caso não o sejam, são apenas aspirações. Nas palavras do autor:

I believe it is wiser to elaborate normative arguments on the value of political constitutions by using history to compare past with present or the institutions of one country with those of another. This avoids the awkwardness of having to shift from an ideal model to the political and social reality we are trying to understand. (VIROLI, 2002, p. 60).

Outra crítica republicana ao liberalismo refere-se precisamente ao conceito liberal de liberdade. Para o liberalismo, a força, a ameaça ou a coerção constituem-se como as únicas formas de constrangimento que podem interferir na liberdade individual. Aproximando-se da definição republicana de liberdade como não-dependência - tal como formulada por Pettit (2004) -, Viroli (2002) argumenta que, para além das distintas formas 
possíveis de constrangimento identificadas pelo liberalismo, os republicanos levam em consideração também a dependência e suas implicações restritivas à liberdade.

Tal diferença na concepção de liberdade entre republicanos e liberais tem implicações nas posições assumidas em relação às leis. Como foi previamente argumentado com base em Pettit (2004), enquanto que para os liberais as leis são encaradas como uma forma de interferência no campo de ação individual e, por consequência, como uma forma de restrição da liberdade, para os republicanos as leis são consideradas mecanismos adequados a uma república, sendo responsáveis pela liberdade gozada por seus cidadãos.

Contrapondo-se a John Rawls, que em sua formulação sobre os princípios de justiça irá adotar a noção kantiana de autonomia, os republicanos afirmam que a vontade autônoma não se dá quando as leis e as regulações correspondem à vontade do indivíduo, mas precisamente quando elas o protegem do perigo constante de ser sujeitado à coerção e a constrangimentos. Tal contraposição expressa uma das fragilidades teóricas imputadas ao liberalismo por Viroli (2002), a saber, o ahistoricismo de Rawls na elaboração da posição originária como o momento de criação de leis, que corresponderiam à vontade dos indivíduos livres e racionais.

Em suma, autores neorrepublicanos como Pettit, Skinner e Viroli rejeitam a ideia de que ser livre significa obedecer a leis que nós mesmos aprovaríamos. As ações reguladas pela lei são livres quando as leis não são arbitrárias, isto é, quando elas são universais, aplicadas a civis e governantes. A universalidade das leis protege os cidadãos do constrangimento arbitrário de outros e do Estado, tornando possível que as vontades individuais sejam completamente autônomas. Para o republicanismo, a diferença entre a restrição causada pelas leis e a restrição causada por uma vontade arbitrária é a diferença entre a obediência e a servidão.

\section{UM ESBOÇO DE CRÍTICA SOCIOLÓGICA AO DEBATE SOBRE A LIBERDADE}

\subsection{A liberdade e a agência: entre a teoria política e a sociologia}

Com base na argumentação apresentada até o momento, podemos passar à exposição do que constitui a contribuição substantiva e original deste artigo. Ela consiste 
na demarcação de uma distinção fundamental na discussão sobre a liberdade nos âmbitos da teoria política e da sociologia. Tal distinção se funda, principalmente, em dois aspectos: por um lado, em termos da própria constituição teórica e epistemológica de tais campos disciplinares; por outro, em função do objeto de referência considerado para a análise da liberdade e suas restrições. No que tange à teoria política, pode-se argumentar que tal campo teórico sustenta-se na filosofia moral - dependendo, por conseguinte, de juízos de valor acerca do que constitui uma boa sociedade e sobre a própria natureza do homem -, tratando a questão da liberdade tendo em mente a interferência oriunda das esferas da política e do Estado. Em contrapartida, uma discussão sociológica sobre a liberdade, orientada a partir de um ponto de vista científico e objetivado - isto é, de um esforço que visa controlar e explicitar os julgamentos valorativos e morais -, irá considerar a "sociedade" como a unidade de referência para a análise das restrições à liberdade. Neste sentido, em sociologia o problema da liberdade acaba por reconfigurar-se, qualificando-se como o problema da agência, isto é, das possibilidades da ação social "livre" do indivíduo em face da determinação e da estruturação social ${ }^{8}$. Ao apresentar uma crítica às concepções sobre a liberdade na teoria política - notadamente aos conceitos liberal e republicano de liberdade -, introduzindo outra forma de análise possível para o fenômeno da dominação e da interferência externa à ação do indivíduo - isto é, ao introduzir uma perspectiva sociológica sobre o problema da "liberdade" -, o presente artigo tem por objetivo executar uma clarificação do debate na interface de dois campos disciplinares, avaliando a pertinência e a área de competência de cada um deles para a análise dos constrangimentos políticos e sociais à ação do homem.

Como argumenta Isaiah Berlin (2002, p. 228): “A teoria política é um ramo da filosofia moral que parte da descoberta, ou aplicação, de noções morais na esfera das relações políticas”. Will Kymlicka (2006, p. 278-9), no mesmo sentido, irá afirmar que a precedência do indivíduo em John Rawls - e no liberalismo - não é uma afirmação sociológica, mas moral. É nesse sentido que podemos compreender e qualificar o individualismo moral subjacente ao liberalismo: o indivíduo é a unidade básica do valor moral para a definição das relações políticas. A teoria política, enquanto ramo da filosofia, propõe-se a analisar e justificar moralmente as instituições políticas e, para tanto, não pode prescindir de concepções morais sobre a natureza do homem.

\footnotetext{
${ }^{8} \mathrm{O}$ sociólogo americano Jeffrey Alexander irá argumentar que os esforços de sociólogos para conjugar a teoria da ação com a estrutura - isto é, para a formulação de uma teoria sociológica que dê conta simultaneamente da agência e dos determinantes sociais - irá constituir, na década de 1980, um "novo movimento teórico", que orientará o debate sociológico posterior (ALEXANDER, 1987).
} 
É imperioso que distingamos a perspectiva sociológica da perspectiva teóricopolítica, caso contrário o conceito de liberdade ver-se-á interposto em uma penumbra, sofrendo limitações incontornáveis. Em nossa visão, 0 individualismo e, consequentemente, a primazia do eu e a defesa de uma área mínima de não interferência à conduta do indivíduo, só podem ser sustentados tomando-se como categoria de referência o Estado. Dito de outro modo, os conceitos de liberdade mostram-se pertinentes no âmbito da política, isto é, definindo uma área de não interferência básica ou de não dominação por parte do Estado e de outros indivíduos.

Não obstante, os teóricos políticos carecem de clareza analítica quanto ao agente de tal interferência. Haveria, assim, uma confusão entre as esferas do político e do social. Essa clarificação é essencial, haja vista que os teóricos políticos parecem confundir a interferência do Estado com a interferência da sociedade: Berlin (2002), por exemplo, falará de liberdade em relação ao "controle social", e Rawls (1993) sustentará que a teoria da justiça depende de uma teoria da sociedade - que se mostra extremamente frágil em seu esquema teórico.

Discutindo a temática da busca por status e reconhecimento - que não poderia ser compreendida nem como liberdade negativa nem positiva, isto é, não constituiria um terceiro conceito de liberdade -, e apontando a influência das interações sociais para a constituição da identidade pessoal, Berlin (2002, p. 257) argumenta que: "Na medida em que vivo em sociedade, tudo o que faço afeta inevitavelmente o que os outros fazem e é afetado por isso". Em outras palavras, Berlin concorda que escapar de características essenciais - algumas sociais - é impossível. De modo semelhante, Kymlicka (2006) reconhece que nossa concepção de bem está ligada às práticas culturais que compartilhamos com os demais membros de uma comunidade. Ainda assim, do nosso ponto de vista, as formulações sobre a sociedade e a análise das influências e dos constrangimentos sociais aos indivíduos não são desenvolvidas de forma satisfatória pela teoria política.

Em nossa visão, se considerarmos que o conceito de liberdade negativa envolve a não interferência de forças da sociedade - consideremos, por exemplo, agrupamentos como a "família", a "escola", as "seitas religiosos", etc. -, a conclusão óbvia é de que nunca houve liberdade - ou, ao menos, que a liberdade nas sociedades modernas é ínfima. Dito de outro modo, quando a categoria de referência para a interferência deixa de ser o Estado, passando a ser a "sociedade" - compreendida no sentido de relações sociais de interdependência, que formam o mundo social -, o conceito de liberdade 
negativa mostra-se contraproducente, na medida em que não existe nenhuma área da vida de um indivíduo em que não haja interferência - ainda que não deliberada - de elementos ou forças sociais. É por tal motivo que, no que tange ao problema da liberdade, sustentamos a necessidade da separação analítica entre o Estado e a sociedade e, por consequência, entre a teoria política e a sociologia.

Deve-se pontuar que a liberdade enquanto conceito normativo, tal como é compreendida pelos liberais, implica a interferência deliberada à ação dos indivíduos. Note-se que a interferência ou coerção social não é necessariamente deliberada; por consequência, ela não implicaria falta de liberdade política. Não obstante, os determinantes sociais interferem ou restringem - de modo inegável - a ação dos indivíduos. Neste sentido, argumenta-se que a análise de constrangimentos à ação "livre" do indivíduo por parte de forças sociais - isto é, a análise de forças externas de interferência ou de dominação na conduta do indivíduo -, é tanto possível como necessária. Para tanto, tendo em vista a garantia do rigor e da coerência conceitual, será essencial mudar os termos empregados na análise: ao invés de "liberdade", devemos nos referir à "agência". Destarte, para uma reflexão acerca dos constrangimentos sociais à ação dos indivíduos - de natureza não deliberada e não intencional -, devemos nos voltar a uma discussão sobre as possibilidades da agência social.

\subsection{0 individualismo e o problema da natureza humana na sociologia}

Antes de passarmos à análise do problema da agência, examinemos brevemente alguns pressupostos sociológicos - marcados por uma perspectiva não moral - sobre a "natureza" do homem 9 . Como se sabe, a teoria política é largamente influenciada pelo individualismo - fruto da hegemonia do pensamento liberal. Em tal perspectiva, tudo se passa como se o indivíduo, livremente e por suas próprias capacidades, criasse um ente maior como o "Estado" ou a "sociedade". Esse é o pano de fundo de todas as pífias versões do contratualismo. Portanto, a perspectiva liberal e contratualista baseia-se numa concepção individualista de sociedade.

\footnotetext{
${ }^{9}$ A questão da "natureza do homem" é complexa em sociologia, sendo impossível tratá-la de modo satisfatório aqui. Grosso modo, supõe-se que o "humano" é resultado de processos de socialização, e que a individualidade é construída socialmente. Todavia, alguns sociólogos - como Elias (1994) - não negam a existência de elementos pulsionais e instintivos, controlados no processo civilizatório.
} 
Para problematizarmos tal concepção, podemos - à maneira de Norbert Elias defini-la como a do homo clausus, isto é, do homem fechado em si mesmo. Discutindo a obra de Sigmund Freud, Elias e Scotson (2000) argumentam que os trabalhos do autor contribuíram para esclarecer os processos grupais que influenciam as funções de autocontrole do indivíduo. Não obstante, criticando os trabalhos do pai da psicanálise, os autores argumentam que Freud concebia as funções de autocontrole como se operassem de forma autônoma dentro do indivíduo. Desta forma, Freud ignoraria os processos de socialização e de aprendizagem. Nas palavras dos autores:

Por mais que ele [Freud] tenha contribuído para a compreensão dos laços que unem as pessoas, seu conceito do homem continuou a ser, basicamente, o do indivíduo isolado. Em seu campo de visão, as pessoas pareciam estruturadas $e$ as sociedades formadas por pessoas interdependentes afiguravam-se um pano de fundo, uma "realidade" não estruturada, cuja dinâmica, aparentemente, não exercia nenhuma influência no ser humano individual. (ELIAS; SCOTSON, 2000, p. 42, grifo dos autores).

O conceito de homo clausus, bem como a crítica de Elias e Scotson (2000) ao individualismo freudiano, adéqua-se perfeitamente para uma definição da concepção liberal individualista do homem. Em outras palavras, pode-se dizer que o indivíduo livre de interferência social é um abstrato homo clausus, não estruturado e fechado em si mesmo. Em tal visão, um conjunto de seres humanos isolados formariam instituições de ordem maior - as instituições políticas. Assim, a sociedade seria o resultado da combinação de um conjunto de indivíduos isolados, enquanto os fins políticos resultariam de uma combinação de preferências individuais produzidas autonomamente.

Subjaz à sociologia elisiana uma crítica às várias versões da teoria atomística, que concebe as configurações sociais como massas de átomos individuais. Em tal visão, supõe-se a existência de ações individuais pré-sociais, bem como de átomos individuais anteriores às unidades que compõem - isto é, anteriores às figurações. O cerne da crítica de Elias a Freud direciona-se à dissociação da identidade individual da identidade dos grupos. De tal modo, sociologicamente falando, podemos argumentar que a individualidade, a personalidade e a identidade só podem ser compreendidas enquanto categorias socialmente construídas. 


\subsection{O problema da agência na sociologia}

Passemos agora à discussão sobre o problema da agência, tomando por base as proposições da sociologia de Pierre Bourdieu. O principal conceito à discussão é o de habitus, noção que visa operar uma síntese entre as perspectivas objetivista e subjetivista, postulando a indissociabilidade entre a agência e a estrutura - ou, em outros termos, entre o indivíduo e a sociedade. O habitus é compreendido por Bourdieu como um princípio que rege a ação, possibilitando e determinando a agência. $O$ habitus é constituído de estruturas sociais incorporadas, estruturas estruturantes da agência e estruturas estruturadas socialmente. No trecho a seguir, em que Bourdieu define o habitus enquanto saber incorporado de ordem prática, podemos constatar também uma crítica às formulações orientadas segundo a perspectiva da liberdade negativa:

Se de maneira alguma se exclui que as respostas do habitus se acompanham de um cálculo estratégico que tende a realizar de um modo consciente a operação que o habitus realiza de um outro modo, a saber, uma estimativa das possibilidades que supõe a transformação do efeito passado em objetivo esperado, o fato é que elas se definem antes, fora de qualquer cálculo, em relação às potencialidades objetivas, imediatamente inscritas no presente, coisas para fazer ou não fazer, dizer ou não dizer, em relação a um por vir provável que, ao contrário do futuro como "possibilidade absoluta" (absolute Möglichkeit), no sentido de Hegel (ou de Sartre), projetada pelo projeto puro de uma "liberdade negativa", propõe-se com uma urgência e uma pretensão em existir que exclui a deliberação. (BOURDIEU, 2009, p. 88, grifos do autor).

Em sua célebre obra $A$ distinção: crítica social do julgamento, Bourdieu (2007) argumenta que é por meio do habitus que um conjunto de indivíduos que partilha uma mesma posição no espaço social - isto é, uma "classe social", determinada pelo volume e pela estrutura de capitais - irá assumir um estilo de vida coerente (BOURDIEU, 2007; BOURDIEU, 1996). Com base em uma extensa pesquisa empírica, constituída por entrevistas e análises estatísticas, Bourdieu (2007) demonstrará que as múltiplas e variadas tomadas de posição dos agentes - posicionamentos políticos, gostos estéticos e estilos de vida em sentido amplo - são determinadas pela posição ocupada pelos agentes no espaço social. Tais tomadas de posição envolvem uma série de liberdades consideradas invioláveis pela tradição liberal: a liberdade de escolha, a liberdade pessoal, de pensamento, de opinião, de expressão, etc. Em outras palavras, tais "liberdades" 
sofrem a interferência de determinantes sociais e da posição social ocupada pelo indivíduo.

Assim, subjaz à sociologia de Bourdieu uma tese extremamente pertinente à nossa discussão, a saber, a de que a "agência" do indivíduo não é inteiramente "livre", na medida em que é condicionada pelo espaço social. Por consequência, podemos argumentar que atributos considerados pela teoria política como inalienáveis da liberdade dos indivíduos são, na verdade, o resultado da influência e da interferência de fatores e de condicionantes sociais. De tal modo, em termos sociológicos, depreende-se que as escolhas, os gostos e os posicionamentos dos indivíduos - atributos constitutivos da "liberdade" na perspectiva liberal - são determinados pela posição particular que tais agentes ocupam no espaço social - para empregarmos a terminologia de Pierre Bourdieu -, ou pela figuração social específica da qual fazem parte - nos termos sugeridos por Norbert Elias.

\section{4 problema da dependência e da dominação: entre 0 republicanismo e a sociologia}

Em nossa apresentação da noção de liberdade como não-dominação ou nãodependência, expusemos três ideias basilares a tal concepção de liberdade: (1) as leis criam a liberdade de que gozam os cidadãos; (2) as leis precisam ser universais para que efetivamente assegurem a liberdade; e (3) a liberdade é, por conseguinte, uma condição ou status político, que protege os cidadãos do constrangimento arbitrário de outros e do Estado, tornando possível que as vontades dos indivíduos sejam completamente autônomas. O cerne de tal concepção de liberdade e do seu valor teórico consiste no estabelecimento de uma delimitação política às ações dos indivíduos e do Estado. Tal delimitação tem por objetivo impedir a existência de relações de dependência e de dominação, cujo modelo exemplar é a relação entre senhor e escravo.

Quando nos voltamos para uma elaboração sociológica das noções de dependência e de dominação, ou seja, quando saímos da particularidade do domínio da política e nos voltamos para outras formas de relação, os usos de ambas as noções adquirem outra conotação. Norbert Elias, através do seu conceito de figuração (ou "configuração"), irá definir a sociedade precisamente como uma teia de interdependências funcionais entre os indivíduos. Nas palavras do autor: 
A rede de interdependências entre os seres humanos é o que os liga. Elas formam o nexo do que é aqui chamado configuração, ou seja, uma estrutura de pessoas mutuamente orientadas e dependentes. Uma vez que as pessoas são mais ou menos dependentes entre si, inicialmente por ação da natureza e mais tarde através da aprendizagem social, da educação, socialização e necessidades recíprocas socialmente geradas, elas existem, poderíamos nos arriscar a dizer, apenas como pluralidades, apenas como configurações. [...] O conceito de configuração foi introduzido exatamente porque expressa mais clara e inequivocamente o que chamamos de "sociedade" [...], não sendo nem uma abstração de atributos de indivíduos que existem sem uma sociedade, nem um "sistema" ou "totalidade" para além dos indivíduos, mas a rede de interdependências por eles formada. (ELIAS, 1994, p. 249).

Com base na formulação de Elias, é possível estabelecer uma distinção entre os usos da noção de dependência entre os domínios da teoria política e da sociologia. Enquanto a noção de dependência é mobilizada pela teoria política republicana para a construção de um modelo normativo de liberdade política - baseando-se em um tipo específico de relação observado na história -, a sociologia irá empregar o conceito para explicar e demonstrar os processos de constituição, estruturação e reprodução da sociedade.

Mobilizando uma vez mais a sociologia elisiana, desta vez a partir da releitura do historiador social Roger Chartier - desenvolvida no prefácio da célebre obra $A$ Sociedade de Corte (ELIAS, 2001) -, vejamos de que modo o autor irá compreender a noção de "liberdade":

\footnotetext{
Elias prefere pensar a "liberdade" de cada indivíduo como inscrita na cadeia de interdependências que o liga aos outros homens e que limita o que lhe é possível decidir ou fazer. Contra as categorias idealistas do indivíduo em si [...] ou da pessoa pura [...], contra uma representação atomística das sociedades, que as considera apenas a agregação de sujeitos isolados e a soma de comportamentos pessoais, Elias coloca como centrais as redes de dependências recíprocas que fazem com que cada ação individual dependa de toda uma série de outras, porém modificando, por sua vez, a própria imagem do jogo social. (CHARTIER, 2001, p. 13).
}

Como argumenta Viroli (2002), a noção republicana de liberdade é, do ponto vista teórico, mais rica e coerente do que a concepção liberal. Uma das razões é por não tomar como base para a sua definição um ponto de partida hipotético - à maneira de Rawls -, mas, ao contrário, por fundamentar a sua definição historicamente. Não obstante, a ideia de que a autonomia da vontade dependa exclusivamente do pertencimento a uma 
comunidade política que assegure um status de não dependência ao indivíduo evoca, em nossa visão, traços do característico individualismo da teoria política, conforme indicamos anteriormente.

A crítica à concepção do homo clausus elaborada por Elias, bem como a noção de habitus formulada por Bourdieu, constituem-se como esforços para demonstrar um fato sociológico, a saber, que as vontades individuais são socialmente estruturadas. A ideia de que a não dependência, no sentido republicano, seja a condição exclusiva para a autonomia da vontade, representa uma formulação sociologicamente infértil. Dito de outro modo, o simples fato de um indivíduo não estar na condição política de escravo, não implica que ele esteja livre de toda uma multiplicidade de determinantes sociais, os quais são parte estruturante e constitutiva das vontades individuais.

Na mesma linha de raciocínio, podemos elaborar uma distinção similar em relação aos usos da noção de "dominação". Devido ao modelo exemplar da relação senhor e escravo, a concepção republicana de liberdade compreende, em sentido político, as noções de dominação e de dependência como idênticas. Como vimos, ser dependente da vontade arbitrária de outro é ser dominado por ele.

Entretanto, pode-se argumentar que as relações de dominação não estão circunscritas ao âmbito da política, mas são constitutivas das relações sociais de modo geral. Neste sentido, os usos da noção de dominação em sociologia adquirem conotações distintas. Pierre Bourdieu, por exemplo, irá utilizar o conceito de dominação para descrever como os sistemas simbólicos, instrumentos de conhecimento e de comunicação, operam a imposição de princípios de classificação do mundo social. Tais princípios de classificação são produzidos e disputados dentro dos campos sociais.

Para Bourdieu (2004), o mundo social é composto por diversos campos econômico, político, cultural, artístico, científico, etc. -, constituídos como espaços de relações objetivas que possuem uma autonomia relativa em relação a outros campos isto é, a lógica interna de determinado campo não pode ser reduzida à lógica de outro. Os campos possuem uma dinâmica dupla, como "campo de forças" que constrange os agentes que estão inseridos nele para se orientarem segundo a lógica dominante do espaço, e também como "campo de lutas", voltadas para a apropriação de capitais ou para a redefinição da doxa vigente em cada campo.

Segundo Bourdieu (2004), os capitais são desigualmente distribuídos entre os agentes, sendo tal desigualdade determinante para a estrutura de posições em determinado espaço, concebida a partir de uma oposição entre posições dominantes - 
ocupadas por agentes detentores do capital "legítimo" - e posições dominadas. Os "dominantes" e "dominados" em determinado campo concorrem para o estabelecimento dos critérios considerados "legítimos" no espaço, bem como para alterar sua posição na hierarquia interna do campo.

De tal modo, podemos afirmar que, em uma perspectiva sociológica, a dominação e a existência de hierarquias é uma realidade sine qua non da experiência social, estruturando a lógica e a dinâmica das práticas sociais nos distintos espaços. Assim, se para a teoria política de matriz republicana a dominação é condição de inexistência de liberdade política, para a sociologia as relações de dominação são um fenômeno inescapável e constitutivo do mundo social.

\subsection{Algumas considerações finais}

Como foi argumentado, o reconhecimento do apanágio social da individualidade não implica recair no argumento comunitarista, que postula o bem comum como valor moral último de um agrupamento político, situando-o acima do indivíduo. Significa dizer, tão somente, que o indivíduo é formado, constituído, determinado e constrangido socialmente, definindo sua individualidade por meio de processos de socialização. $\mathrm{Na}$ visão comunitarista, as restrições coletivas e sociais à ação dos indivíduos não implicariam uma perda de liberdade, haja vista que elas possibilitariam a autodescoberta da "verdadeira" identidade do indivíduo e promoveriam o bem comum. Tal formulação é, obviamente, insustentável de um ponto de vista sociológico. A concepção comunitarista recai em um coletivismo que substancializa as identidades, além de mostrar-se inteiramente dependente de concepções morais sobre a natureza do homem. Uma discussão sociológica, ao contrário, prescinde de pressupostos morais, analisando objetivamente os processos sociais que constituem os indivíduos e o mundo social.

Demonstrar que os conceitos de "liberdade como não-interferência" ou de "liberdade como não-dominação" não se aplicam quando tomamos a sociedade como categoria de referência, tampouco implica incorrer em um conceito "positivo" de liberdade. Tal constatação não implica o postulado da existência de uma "razão latente" ou "verdadeira", em relação à qual todos os membros de uma coletividade deveriam se orientar, em virtude de sua constituição intrinsecamente racional. Em uma perspectiva sociológica, supõe-se o caráter contingente e "arbitrário" - isto é, não necessário e não 
essencial - das estruturas, das normas e das instituições sociais. Nosso argumento, assim, sugere que mesmo não sendo uma expressão da razão pura ou prática, as estruturas sociais se impõem de forma manifesta e concreta aos agentes sociais.

Podemos constatar a influência de elementos de ordem social em todas as esferas da existência dos indivíduos, o que traz limitações incontornáveis aos conceitos de liberdade como não-interferência e não-dominação. A linguagem, as tecnologias e as ideias à disposição - para mencionarmos alguns exemplos - são produzidas socialmente, delimitando objetivamente as possibilidades de ação do indivíduo. As normas sociais, os códigos de conduta e os valores morais constrangem os indivíduos e o seu comportamento. Para mencionarmos Norbert Elias (2001, p. 264) uma vez mais: "Uma convivência social sem coerções é [...] inimaginável e impossível”. Assim, não existe um indivíduo puro, ideal e atomizado, que não sofra interferência ou dominação na sua existência social, e menos ainda um indivíduo que não esteja situado e referenciado histórica e socialmente. Em suma, em termos sociológicos, constata-se que não há nenhuma esfera da vida de um indivíduo que não sofra a influência dos demais, na medida em que ele está inserido em redes de relação e de interdependência.

Ainda assim, ao considerarmos o problema da interferência e da dominação política - domínio par excellence da teoria política -, estamos dispostos a aceitar o pressuposto filosófico-moral postulado pelo liberalismo e pelo republicanismo como condição necessária à liberdade, a saber, a garantia das possibilidades de ação "livre" dos indivíduos em face à interferência do Estado, ou à dominação arbitrária de outros indivíduos. Tal suposição, que se baseia na premissa sociologicamente insustentável da primazia do eu e do indivíduo é, não obstante, imprescindível para a regulação das relações políticas e para a própria possibilidade da liberdade.

Neste sentido, deve-se apontar que uma das principais constatações da nossa discussão é a identificação e o reconhecimento de um paradoxo que, até o momento, nos parece inescapável. Isto é, não se pode justificar em termos lógicos a primazia do eu, mas não se pode prescindir de tal premissa no domínio político. Dito de outro modo, se sociologicamente não se pode admitir a precedência moral ou lógica do indivíduo, tal premissa é indispensável para a preservação do indivíduo em relação às arbitrariedades do Estado, bem como para a garantia da liberdade e da cidadania. Tal paradoxo expressa, ademais, as diferenças fundamentais entre a teoria política e a sociologia, tais como as definimos: por um lado, a perspectiva moral em contraposição à perspectiva 
objetiva e, por outro, a interferência política do Estado (a ser evitada) em oposição à interferência social (inescapável).

\section{REFERÊNCIAS}

ALEXANDER, Jeffrey C. O novo movimento teórico. Revista Brasileira de Ciências Sociais, São Paulo, v. 2, n. 4, jun. 1987.

BERLIN, Isaiah. Dois conceitos de liberdade. In: BERLIN, Isaiah. Estudos sobre a humanidade: Uma antologia de ensaios. São Paulo: Companhia das Letras, 2002. p. 226-272.

BOURDIEU, Pierre. A distinção: Crítica social do julgamento. São Paulo: Edusp; Porto Alegre: Zouk, 2007.

BOURDIEU, Pierre. O senso prático. Petrópolis: Vozes, 2009.

BOURDIEU, Pierre. Os usos sociais da ciência: Por uma sociologia clínica do campo científico. São Paulo: Editora UNESP, 2004.

BOURDIEU, Pierre. Razões práticas: Sobre a teoria da ação. Campinas: Papirus, 1996.

CHARTIER, Roger. Prefácio. In: ELIAS, Norbert. A sociedade de corte: Investigação sobre a sociologia da realeza e da aristocracia de corte. Rio de Janeiro: Jorge Zahar Ed., 2001. p. 7-25

DURKHEIM, Émile. Lições de Sociologia. 2. ed. São Paulo: Martins Fontes, 2013.

ELIAS, Norbert. A sociedade de corte: Investigação sobre a sociologia da realeza e da aristocracia de corte. Rio de Janeiro: Jorge Zahar Ed., 2001.

ELIAS, Norbert. O processo civilizador. Volume I: Uma história dos costumes. 2. ed. Rio de Janeiro: Jorge Zahar Ed., 1994.

ELIAS, Norbert; SCOTSON, John L. Os estabelecidos e os outsiders: Sociologia das relações de poder a partir de uma pequena comunidade. Rio de Janeiro: Jorge Zahar Ed., 2000.

GIDDENS, Anthony. A sociologia política de Durkheim. In: GIDDENS, Anthony. Política, sociologia e teoria social: Encontros com o pensamento social clássico e contemporâneo. São Paulo: Ed. Unesp, 2011.

KYMLICKA, Will. O comunitarismo. In: KYMLICKA, Will. Filosofia política contemporânea: Uma introdução. São Paulo: Martins Fontes, 2006. p. 253-301.

MILL, John Stuart. Sobre a liberdade. In: WEFFORT, Francisco C. (Org.). Os clássicos da política. 2. v. 10. ed. São Paulo: Ática, 2001. p. 200-215. 
PETTIT, Philip. Liberalismo y Republicanismo. In: OVEJERO, Félix; MARTI, José Luis; GARGARELLA, Roberto (Orgs.). Nuevas ideas republicanas: Autogobierno y libertad. Barcelona: Paidós, 2004. p. 115-135.

RAWLS, John. A justiça como equidade (Trechos extraídos dos capítulos 1 a 5 de Uma teoria da justiça, Brasília, Editora da UnB, 1981). In: KRISCHKE, Paulo J. (Org.). 0 contrato social, ontem e hoje. São Paulo: Cortez, 1993. p. 155-191.

SANDEL, Michael. La república procedimental y el yo desvinculado. In: OVEJERO, Félix; MARTÍ, José Luis; GARGARELLA, Roberto (Orgs.). Nuevas ideas republicanas: Autogobierno y libertad. Barcelona: Paidós, 2004. p. 75-92.

SILVA, Ricardo. Visões da liberdade: republicanismo e liberalismo no debate teórico contemporâneo. Lua Nova, São Paulo, n. 94, p. 181-215, abr. 2015.

SKINNER, Quentin. A Third Concept of Liberty: Living in Servitude. London Review of Books, Londres, v. 24, n. 7, p. 237-268, abr. 2002.

VIROLI, Maurizio. Republicanism. New York: Hill \& Wang, 2002.

\section{NOTAS}

\section{TÍTULO DA OBRA}

O debate da teoria política contemporânea sobre a "liberdade" e um esboço de crítica sociológica

\section{Lucas Voigt}

Doutorando junto ao Programa de Pós Graduação em Sociologia da Universidade Federal do Rio Grande do Sul (PPGS/UFRGS)

Universidade Federal do Rio Grande do Sul, Porto Alegre, Brasil

lucas_3106@hotmail.com

(1) https://orcid.org/0000-0001-9789-7851

\section{Jean Matheo Piccini Lago}

Mestre em Sociologia Política

Universidade Federal de Santa Catarina, Departamento de Sociologia e Ciência Política, Florianópolis, Brasil jean8884@hotmail.com

Ohttps://orcid.org/0000-0002-4197-3859

\section{Endereço de correspondência do principal autor}

Não se aplica.

\section{FINANCIAMENTO}

CAPES.

\section{CONFLITO DE INTERESSES}

Não se aplica.

\section{LICENÇA DE USO}

Os autores cedem à Em Tese os direitos exclusivos de primeira publicação, com o trabalho simultaneamente licenciado sob a Licença Creative Commons Attribution 4.0 Internacional (CC BY). Esta licença permite que terceiros remixem, adaptem e criem a partir do trabalho publicado, atribuindo o devido crédito de autoria e publicação inicial neste periódico. Os autores têm autorização para assumir contratos adicionais separadamente, para distribuição não exclusiva da versão do trabalho publicada neste periódico (ex.: publicar em repositório institucional, em site pessoal, publicar uma tradução, ou como capítulo de livro), com reconhecimento de autoria e publicação inicial neste periódico.

\section{PUBLISHER}

Universidade Federal de Santa Catarina. Programa de Pós-Graduação em Sociologia e Ciência Política. Publicado no 
Portal de Periódicos UFSC. As ideias expressadas neste artigo são de responsabilidade de seus autores, não representando, necessariamente, a opinião dos editores ou da universidade.

\section{HISTÓRICO}

Recebido em: 25 de julho de 2018

Aprovado em: 12 de março de 2019 